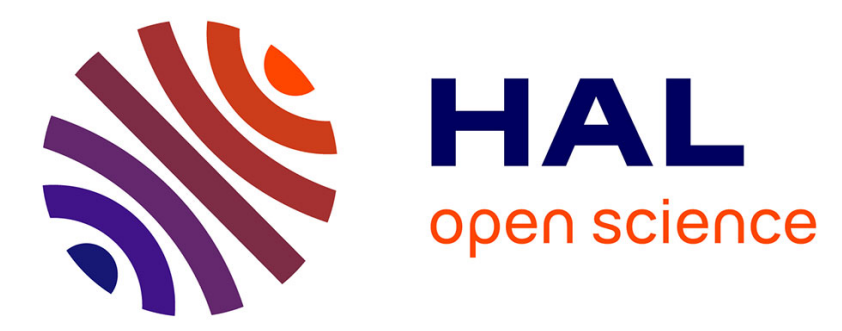

\title{
"Same, same but different": The optimal viewing position effect in developmental dyslexia, developmental coordination disorder and comorbid disorders
}

Stéphanie Bellocchi, Stéphanie Ducrot

\section{- To cite this version: \\ Stéphanie Bellocchi, Stéphanie Ducrot. "Same, same but different": The optimal viewing position ef- fect in developmental dyslexia, developmental coordination disorder and comorbid disorders. Dyslexia, 2021, 27 (3), pp.294-311. 10.1002/dys.1688 . hal-03366867}

\section{HAL Id: hal-03366867 \\ https://hal.science/hal-03366867}

Submitted on 4 Jan 2022

HAL is a multi-disciplinary open access archive for the deposit and dissemination of scientific research documents, whether they are published or not. The documents may come from teaching and research institutions in France or abroad, or from public or private research centers.
L'archive ouverte pluridisciplinaire HAL, est destinée au dépôt et à la diffusion de documents scientifiques de niveau recherche, publiés ou non, émanant des établissements d'enseignement et de recherche français ou étrangers, des laboratoires publics ou privés. 


\title{
DISORDERS
}

3

"Same, same but different":

The OVP effect in developmental dyslexia, developmental coordination disorder and comorbid disorders

\begin{abstract}
The Optimal Viewing Position (OVP) effect indicates that words are identified most quickly when the eyes fixate near the word centre in alphabetic languages. In two studies, we tested OVP in typically developing readers and children with developmental dyslexia (DD), developmental coordination disorder (DCD) and with both disorders (DD+DCD), using a variable-viewing-position technique. Study 1 showed that typically developing readers had developed highly automatized procedures of left-to-right attentional scanning resulting in an inverted $J$-shape VP curve comparable to what is observed in adult readers and that dyslexics showed non-prototypical one. In Study 2 we observed more typical procedures of left-to-right attentional scanning in children with DCD, isolated or comorbid, compared to DD. Moreover, given the absence of significant group differences between children with DD+DCD and children with isolated DD or DCD, our results reinforce the idea that the comorbid condition does not add to the severity of OVP anomalies. We then concluded that OVP atypicalities are specific to children with DD. Finally, we discussed the usefulness of the OVP effect as a clinical tool to identify possible OVP atypicalities that could be specific of some neurodevelopmental disorders (i.e., DD, DCD or DCD+DD).
\end{abstract} Keywords: developmental dyslexia, developmental coordination disorder, comorbidity, optimal viewing position, reading 


\section{INTRODUCTION}

Learning to read naturally requires the development of a number of strictly linguistic skills (e.g., phonological awareness, phonological short-term memory, lexical knowledge, etc.) (e.g. Goswami \& Bryant, 1990). However, processing written language also requires a visual analysis that enables the precise decoding of the words. That is, in addition to linguistic skills, children also need to develop good eye-movement control and visual-perceptual skills to learn to read: their visual system has to learn to correctly land the eyes on words, extract the information that is being fixated, program a saccade to the next word position, etc. These visuo-attentional processes must be automatized in order to develop good reading skills (e.g. Bellocchi, Massendari, Grainger, \& Ducrot, 2019; Ducrot, Pynte, Ghio, \& Lété, 2013; Franceschini, Gori, Ruffino, Pedrolli, \& Facoetti, 2012; Grainger, Dufau, \& Ziegler, 2016; Joseph, Liversedge, Blythe, White, \& Rayner, 2009; Vernet, Bellocchi, Leibnitz, Chaix, \& Ducrot, 2021). In other words, to be able to match letters and groups of letters to the phonological representations contained in memory, it is necessary that the child learns to perceive the words. It follows that the efficiency and the rapidity of written word-recognition procedures depend on the quality of perceptual processing. When it comes to reading disabilities, an increasing number of studies shows today that associated visual and oculomotor deficits are present in several neurodevelopmental disorders (e.g., Bellocchi et al., 2019; Gori \& Facoetti, 2015; Martelli et al., 2009; see Bellocchi, Muneaux, Bastien-Toniazzo, \& Ducrot, 2013b and Goswami, 2015, for reviews). Children with developmental dyslexia may show, for example, visual selective attention deficits in automatic orienting and focusing of spatial attention, visuo-attentional span deficits which seem to be independent from a phonological deficit (e.g., Facoetti, Turatto, Lorusso, \& Mascetti, 2001; Valdois, Bosse, \& Tainturier, 2004). Moreover, atypical eye movement patterns during reading have been showed to characterize dyslexics as a manifestation of an impaired cognitive processing (e.g., 
Bellocchi et al., 2019; Gagl, Hawelka, \& Hutzler, 2014; Hawelka, Gagl, \& Wimmer, 2010). Yet the visual aspects of reading acquisition, however fundamental, remain a neglected field of research.

In the current paper, we will focus on the very earliest stages of visual word recognition in both beginning and disabled readers, from the uptake of visual information to sublexical orthographic processing. Visual and attentional factors are thought to have their main impact on reading at this first level of orthographic processing. We examine the importance of these processes for learning to read, and how they can improve our understanding of the difficulties encountered by children showing a specific reading disorder, i.e. those with developmental dyslexia $(D D)^{1}$. In addition, we investigated children with developmental coordination disorder ${ }^{2}(D C D)$, and those with both neurodevelopmental disorders (DD+DCD or comorbid children) in order to explore the impact of comorbidity on these visuo-attentional processes linked to word recognition. Indeed, despite the fact that the association between DD and DCD is a very common condition in neurodevelopmental disorders (Iversen, Berg, Ellertsen, \& Tønnessen, 2005; Kaplan, Dewey, Crawford, Wilson, 2001), very few researches have been developed considering it.

\footnotetext{
${ }^{1}$ Developmental dyslexia is a neurodevelopmental disorder that is diagnosed when no sensory and intellectual deficits can explain reading and/or writing disorders and when adequate instruction and socio-cultural opportunities are available but fail to result in an adequate level of performance [DSM-5, American Psychiatric Association (APA), 2013; W.H.O., 1992]. ${ }^{2}$ Developmental Coordination Disorder is a neurodevelopmental disorder characterized by significant difficulties with the acquisition and execution of motor skill [DSM-5, American Psychiatric Association (APA), 2013]. Individuals with DCD demonstrate a level of motor skill out of keeping with their age and intellectual ability.
} 
Viewing position effects and word recognition in children.

Word recognition involves a reading-specific visual processing mode that relies on the ability to process - simultaneously and in parallel - all the letters of a word in their correct positions. Therefore, the beginning reader's first task consists of developing this ability by mobilizing increasingly rapid, automatic, and irrepressible cognitive processes (Laberge $\&$ Samuels, 1974). One factor known to have a major impact on word reading efficiency in adults is the position of eye fixation in the word (when there is only one fixation). When participants are forced by an experimental manipulation to fixate a word at a specific position, the probability of recognizing it is the highest when the fixation point is to the left of the word's midpoint (for languages read from left-to-right), and it decreases as the eye moves away from this so-called “optimal position” (e.g., O’Regan \& Jacobs, 1992; O’Regan, LevySchoen, Pynte, \& Brugallière, 1984, see Brysbaert \& Nazir, 2005, for a review). This typical pattern of results is the Optimal Viewing Position (OVP) effect, which is characterized not only by the fact that performance is better when the centre of a word is fixated rather than its edges, but also by an asymmetry to the left in the resulting inverted $J$-shape VP function (with a better performance for left-sided than for right sided fixations, i.e., word-beginning superiority effect, Lavidor \&Walsh, 2004).

The OVP effect arises from the rapid drop-off of visual acuity with retinal eccentricity and the fact that more letters from a word can be extracted when the eyes are near the word's center (Brysbaert \& Nazir, 2005; McConkie, Kerr, Reddix, Zola, \& Jacobs, 1989; Nazir, O’Regan, \& Jacobs, 1991; Nazir, Jacobs, \& O’Regan, 1998; but see also Lavidor \& Walsh, 2004 for a theoretical account). It may derive, in addition, from orthographic and lexical/morphological constraints associated with word identification (Clark \& O’Regan, 1999; O’Regan et al., 1984; Stevens \& Grainger, 2003). Given that the most informative letter of words in languages such as English and French is the first letter (see, Grainger, 2017), it 
follows that the OVP emerges at the landing site that maximizes letter perceptibility and minimizes lexical ambiguity. For Brysbaert and colleagues (1996), fixations to the left of the word's centre are less damaging than fixations to the right, because attention can be allocated more rapidly and effectively to the right than to the left in people trained to read in that direction (see also Nazir, Ben-Boutayab, Decoppet, Deutsch, \& Frost, 2004 and Ducrot \& Grainger, 2007). In the same vein, Nazir $(2000 ; 2003)$ proposed that perceptual biases may arise from perceptual learning, with frequently fixated positions becoming optimal for word recognition. According to this report, optimal word recognition is obtained with eye fixation on the location in the word where the eyes prefer to land (i.e. between the beginning and the middle of the word) (Ducrot \& Pynte, 2002; Rayner, 1979). In this line of reasoning, it is important to note that the OVP is dependent on reading habits (right of centre for languages read from right to left; Deutsch \& Rayner, 1999; Farid \& Grainger, 1996). Note also that lexical constraints exerted by the perceived letters on word recognition can affect the shape of the VP curve. For example, low-frequency words are less effectively processed at fixation points away from the OVP (O'Regan \& Jacobs, 1992). Here we argue that the OVP effect can be used to assess the visual processing mode of words being read.

In learning to read, the OVP appears early, even at the end of the first year of reading exposure (Aghababian \& Nazir, 2000; Ducrot et al., 2013), thus suggesting that children extract visual information from print in much the same way as proficient readers do. Given that extraction of visual information is a key component of the OVP effect, then variations in the way visual information is extracted from the input may lead to different VP curves. Following this point of view, Aghababian and Nazir (2000) pointed out that a closer analysis of the VP function might help identify deviant reading behaviours. Accordingly, various “non-prototypical" VP curves are reported in pathological cases: a flat curve in a deaf beginning reader (Aghababian, Nazir, Lançon, \& Tardy, 2001) and a reverted asymmetry in a 
pure alexic patient (Montant, Nazir, \& Poncet, 1998). Ducrot and colleagues (2003) also found differences in dyslexics' VP curve: even though dyslexic children exhibited, as normal readers do, a systematic variation in reading performance when their eyes were fixating different locations in the word (with best recognition performance when the initial fixation was imposed to the left of the word centre), they also showed a symmetrical VP curve. The absence of left-right asymmetry in the VP curve suggests abnormal processing of information outside of foveal vision for dyslexics, as Geiger and colleagues (1992) found, and could thus reflect a deficit in visuo-attentional processing. We found two other reports of such inverted $J$-shaped VP curves in the literature. Dubois et al. (2007) described the case of a young surface dyslexic boy with an atypical VP curve lacking asymmetry and Aghababian and Nazir (2000) reported similar VP patterns in "poor" beginning readers. The variety of VP shapes reported in reading disabilities highlights the need for a better understanding of their visual processing of printed words. However, to our knowledge, there is no well-described in-depth investigation of VP abnormalities in neurodevelopmental disorders. The present paper is a first step in this direction, with a comparison of VP curves in DD, DCD and DD+DCD.

\section{linked to reading?}

Although it's not systematic, co-occurrence between dyslexia and other neurodevelopmental disorders is very common. In particular, epidemiological studies demonstrate a rate of comorbid diagnosis of DCD in 16\% (Kaplan et al., 2001) to $70 \%$ (Iversen et al., 2005) of children with dyslexia. Similarly, Chaix and colleagues (2007) found an high percentage of DCD diagnosis in a group of 58 dyslexics, i.e. $40 \%$ scored below -2 standard deviations (SDs) on the Lincoln-Oseretsky Motor Development Scale (Rogé, 1984), and $17.2 \%$ scored between -1 and -2 SDs. Furthermore, dyslexics proved less successful than 
their peers at carrying on motor tasks (for a review, see Jover, Ducrot, Huau, Bellocchi, BrunHénin, \& Mancini, 2013). For instance, participants with dyslexia demonstrated poor performance on the Movement Assessment Battery for Children (M-ABC; Iversen et al., 2005), pegboard tasks (Nicolson \& Fawcett, 1994), bead threading (Fawcett \& Nicolson, 1995), pointing (Velay, Daffaure, Giraud, \& Habib, 2002), and motor-learning tasks (Bennett, Romano, Howard, \& Howard, 2008). In addition, more relevant for our study is that reading difficulties have been observed in $29 \%$ to $70 \%$ of children diagnosed with DCD (O'Hare \& Khalid, 2002).

Unfortunately, despite the evidence of a frequent association between DD and motor disorders, this co-occurrence is often neglected in the scientific studies exploring reading disabilities and the related cognitive disorders. Furthermore, despite the presence of reading deficits in DCD, to the best of our knowledge, no studies have been published on the role of visuo-attentional processes in reading in children with DCD. In particular, this is even true for studies exploring the landing position patterns, such as the OVP effect. Nevertheless, note that a few studies have explored visuo-attentional processes in DCD. Tsai (2009) observed that DCD children performed worse than typical developing children in an endogenous Posner task measuring visuo-spatial attention. This result is consistent with the huge literature highlighting deficits in the visuospatial information processing in DCD (e.g., Tsai \& Wu, 2008; Wilson \& McKenzie, 1998). However, the majority of these studies used visuo-spatial tasks that didn't directly and precisely measure visuo-spatial attention. In other words, the tasks used belonged to clinical neuropsychology batteries of tests and not to experimental paradigms. The analysis of the literature clearly shows the need to better understand the impact of the co-occurring DCD on the visuo-attentional processes involved in reading by using experimental paradigms (Bellocchi, Muneaux, Huau, Lévêque, Jover, \& Ducrot, 2017). 
The present study focused on the ability of children to recognize briefly displayed single words, while the eyes are fixating a predetermined position within the word. Abnormalities in the developing reading system — although not necessarily "visual" in nature - may nevertheless be apparent in the visual behaviour of the child. Impairments of word recognition performance can differently affect the early stages of visual word processing. The OVP paradigm provides an interesting way to describe the visuo-attentional strategies involved in word recognition by children who have a learning disability and to detect qualitative and quantitative differences in the VP curve of these children. The shape of the VP curve allows to determine the position(s) at which relatively good word processing performance is obtained (maximum of the curve) and at which word processing performance declines (minimum of the curve). The height of the curve allows to evaluate the quality of the lexical competence and the size of the stored lexical knowledge.

The originality of this study resides also on the exploration of the OVP atypicalities in DD and DCD taking into account the co-occurring condition. To the best of our knowledge, this is the first study focusing on that purpose.

First of all, to better understand the specificity of any OVP anomalies within DD, two typically developing comparison groups were recruited, the first matched to children with DD by chronological age (hereafter ' $\mathrm{CA}$ ' group), and the second matched to the DD group by reading level (hereafter 'RL' group). We hypothesized that if DD children show deficits in OVP effect, we should expect that they revealed more marked atypical VP curve (in terms of height and shape) than the CA and RL group; however, if DD children show a delay in OVP effect, we should expect that they underperform only the CA group. These questions will be specifically explored in Study 1. 
Secondly, in order to explore the impact of co-occurence, we compared children with DD and DCD (DD+DCD) to children with isolated disorders (DD or DCD). Consistent with a cumulative hypothesis (e.g. Pitcher, Piek, \& Barrett, 2002), if co-morbid condition add to the severity of the cognitive deficit, children with DD and DCD should revealed more marked atypical VP curve (in terms of height and shape) than children with isolated disorders.

Moreover, the comparison between co-morbid children (DD+DCD) and children with isolated disorders (DD or DCD) can provide evidences about the specificity of the OVP atypicalities to reading or motor impairments. In other words, if OVP anomalies are specifically linked to reading deficits, we should find them in children with specific reading disorder (isolated DD and DD+DCD). However, if OVP anomalies are specifically linked to a motor disorder, we should find them only in DCD children (isolated DCD and DD+DCD). Last but not least, the present study will provide new data on visuo-attentional processing linked to reading in DCD. These questions will be addressed in Study 2.

Finally, even if this was not an objective per se, we aimed at discuss the usefulness of the OVP effect as a clinical tool to identify possible OVP atypicalities that could be specific of some neurodevelopmental disorders (i.e., DD, DCD or DCD+DD). This could constitute an important source of information for practitioners to differentiate cognitive profiles of children with neurodevelopmental disabilities, based upon performance on the OVP.

This research received the agreement of the National Board of Education (project ADIVA). This work was conducted in accordance with the Declaration of Helsinki (WHO, 2008), approved by the local Ethics Committee Review Board (Comité de Protection des Personnes pour la recherche biomédicale, CNRS, France). The children's parents gave their written consent for participation. 


\section{Comparisons between dyslexics and typical developing readers}

In the first study we aimed at exploring the OVP effect in children with DD, as compared to typically developing children matched on chronological age or reading level.

\section{Method} two control groups each composed of 24 typical developing readers, the first of which was matched on chronological age (CA) (mean age in months $=129.66 ; \mathrm{SD}=6.74)$ and the second of which was matched on reading level $(\mathrm{RL})$ (mean age in months $=95 ; \mathrm{SD}=4.47)$.

Participants. A total of 72 children participated in the experiment. They were divided into three groups: one of 24 dyslexics (DD) (mean age in months $=126.95 ; \mathrm{SD}=15.17)$ and Children with DD were recruited and diagnosed in different hospitals or clinical centres based in France: La Timone University Hospital in Marseille, Kremlin-Bicêtre Hospital in Paris and the clinical centre "Les Lavandes" in Orpierre. They all underwent a complete medical, psychological and cognitive assessment. All participants were native speakers of French with normal or corrected-to-normal vision. Children whose oral language skills were in the pathological range or who were diagnosed with ADHD were excluded from the study. Criteria for inclusion were manifest reading deficits (at least 1.5 SDs below the normal level) on the "Alouette Test-R" (Lefavrais, 2005), on IQ measured on the WISC-IV (French version by ECPA, 2005) within the normal limits set by the diagnosis unit (IQ > 85) and no deficits in vision or hearing. More importantly, we selected children without a DCD. As we noted by post-hoc analyses, the mean reading level of the dyslexic children (mean=87.37 months; $\mathrm{SD}=4.94$ months) was significantly below the mean reading level of the chronological age matched group (mean=118.58 months; $\mathrm{SD}=15.12$ months; $p<.001$ ). As expected, the mean reading level of the dyslexic children was comparable from that of the 
reading-level matched children (mean=89.54 months; $\mathrm{SD}=8.25 ; p=\mathrm{ns}$ ) (ANOVA; group effect: $\mathrm{F}(2,71)=68.07 ; p<.001)$

The participants in the two control groups (CA and RL) were recruited from an elementary school (Grade 1 through 5) in a city in southern France, according to their reading level (Grade 1 or 2) and chronological age (Grade 4 or 5) of the dyslexic children. None suffered from any neurological, psychiatric, or emotional disorders or was educationally disadvantaged. The inclusion criteria were a normal reading level and no visual or hearing deficits. We did not include children who were considered by their teachers as having either a specific learning deficit or cognitive and behavioural problems.

Material, task, and stimuli. A pool of 60 words was selected from Manulex (Lété, Sprenger-Charolles, \&Colé, 2004). The stimuli were selected from the first-grade lemma lexicon. Half of the words had a low frequency (LF) - that is, a mean printed frequency of 16 occurrences per million - and the other half were high frequency (HF), with a mean printed frequency of 419 occurrences per million. In each frequency set, $93 \%$ of the words were nouns, $4 \%$ were verbs, and 3\% were adjectives. All words were 5 or 6 letters long. The words used in this work were a subset of the stimuli used in the Ducrot et al.'s previous study (2013). Stimulus presentation was on a Dell Latitude D600 laptop running the DMDX software package (Forster \& Forster, 2001, version 2.9.01). The target words were displayed in white lowercase letters against a black background in 24-point Courier New font, using a 14-inch color monitor, at a resolution of $1024 \times 768$. Participants were seated $60 \mathrm{~cm}$ from the screen. At this distance, one letter subtended a visual angle of $0.5^{\circ}$. Each word was divided into five equally-wide zones (i.e., 1 letter wide for five-letter words and 1.2 letters wide for six-letter words). Words were presented in such a way that subjects initially fixated the centre of each zone (hereafter called positions P1, P2, P3, P4, and P5). Across all participants, each 
word was seen from all five-fixation positions, using different experimental lists. The stimuli were presented in one block with 60 trials. A chin-and-forehead rest was used to minimize head movements. Exposure time for the target was determined individually for each participant, depending on his/her correct identification score on a training session (in which we looked for the presentation duration that produced scores ranging between $50-75 \%$ correct four-letter word identification ${ }^{3}$, i.e., about $100 \mathrm{~ms}$ for CA children, $175 \mathrm{~ms}$ for RL children and $250 \mathrm{~ms}$ for DD). Each trial consisted of the following sequence of events. Participants were first instructed to look at a fixation point at the beginning of each trial, and not to move their eyes. After $500 \mathrm{~ms}$, the fixation point was replaced by a target word that was displayed on the screen for the duration previously determined for that particular child. The word was displaced laterally with respect to the fixation point according to its position condition. Then the word was replaced by a backward mask that consisted of a string of hashes. The task was to identify (name) the target word. If not possible, participants were asked to report as many letters as they could in the correct position. The experimenter manually recorded each participant's response. The mask remained on the screen until the experimenter pressed the spaced bar to trigger the next trial.

Procedure. All children were tested individually: children with neurodevelopmental disorders were tested at the hospital and normal readers in their schools. The session lasted about 15 minutes.

\footnotetext{
${ }^{3}$ In the training session, we used 20 words which were not the same words used in the following test session in order to avoid learning effect.
} 
transformed in arcsine using a 2 Frequency x 5 Positions x 3 groups (dyslexics, chronological-

291 age matched group -CA, and reading-age matched group - RA) ${ }^{4}$. All factors, except Group, were within-participant factors. Effect sizes are reported as eta-square ( $\eta_{2}$, Bakeman, 2005). In order to test the left-right asymmetry of the VP curves we compared performance of word identifications in P1 (left-sided fixation position) vs. P4 and P5 (right-sided positions) ${ }^{5}$, as suggested by other studies (e.g., Ducrot et al., 2013; Stenneken, van Eimeren, Keller, Jacobs, \& Kerkhoff, 2008; Wong \& Hsiao, 2012). Then, pairwise comparisons were run in order to test the specific hypotheses we defined a priori.

Statistical analyses were conducted using the SPSS ${ }^{\circledR}$ program, version 20.0.

\section{Results}

The mean percentage of correct word identifications was calculated for all participants. Table 1 shows descriptive statistics of accuracy as a function of group, frequency of words and letter position.

Table 1. Means and standard deviations of accuracy (percentage of correct responses) as a function of group $(\mathrm{DD}=$ dyslexics; $\mathrm{CA}=$ chronological age control; $\mathrm{RL}=$ reading level control), frequency of words $(\mathrm{HF}=$ High-frequency words; LF= Low-frequency words), and five fixation positions (P1, P2, P3, P, and P5).

\footnotetext{
${ }^{4}$ The assumption of homogeneity of variance was not violated, all $p>.05$ (Levene's test). ${ }^{5}$ Note that P4 and P5 were averaged.
} 


\begin{tabular}{lcccc} 
& & DD & CA & RL \\
\hline & & mean $($ SD $)$ & mean $($ SD) & mean $($ SD) \\
\hline & P1 & $77.78(16.04)$ & $90.97(12.02)$ & $86.10(14.47)$ \\
& P2 & $89.58(15.40)$ & $94.44(10.62)$ & $93.05(9.73)$ \\
& P3 & $84.71(13.82)$ & $95.14(10.40)$ & $88.88(10.62)$ \\
& P4 & $75.00(23.04)$ & $92.36(12.98)$ & $83.55(14.51)$ \\
& P5 & $79.87(20.83)$ & $77.77(19.45)$ & $79.16(18.55)$ \\
\hline & P1 & $38.90(22.35)$ & $75.69(17.00)$ & $57.62(20.73)$ \\
& P2 & $50.69(25.29)$ & $82.64(17.35)$ & $60.10(25.41)$ \\
& P3 & $50.70(28.85)$ & $75.70(17.00)$ & $54.19(24.35)$ \\
& P4 & $42.36(26.91)$ & $67.35(22.78)$ & $47.89(20.03)$ \\
& P5 & $29.86(22.50)$ & $60.40(25.45)$ & $37.00(18.79)$ \\
\hline
\end{tabular}

312

Insert Table 1 about here

The analyses of variance showed that the effect of initial-fixation position on word recognition was consistently significant for all groups $\left[\mathrm{F}(4,276)=23.84 ; p<.001 ; \eta_{2}=.25\right]$. As can be seen in Figure 1a, the location in the words where the recognition curves grew to their maximums was to the left of the target's centre. There was also a significant main effect of frequency $\left[\mathrm{F}(1,69)=439.70 ; p<.0001 ; \eta_{2}=.84\right]$, with an higher recognition probability for HF-words $(86 \%)$ than for LF-words $(55 \%)$. Note that the size of the frequency effect was different for the three groups, as suggested by the interaction between frequency and group [F $\left.(2,69)=7.92 ; p=.001 ; \eta_{2}=.03\right]:$ the frequency effect was attenuated with the increase of reading skills [38.9\% for dyslexics, $32.1 \%$ for RL children, and $17.7 \%$ for CA children]. 

$1.65 ; p=$ n.s.]. However, interestingly, the ANOVA revealed a significant fixation position $\mathrm{x}$

frequency $\mathrm{x}$ group interaction $\left[\mathrm{F}(8,276)=2.14 ; p=.033 ; \eta_{2}=.06\right]$. This three-way interaction is illustrated in Figure 1a. In order to examine the effects of frequency and fixation position in more detail, separate analyses were conducted for each group.

RL-group. The ANOVA revealed a large (32.1\%) frequency effect $[\mathrm{F}(1,23)=$ $\left.176.90 ; p<.001 ; \eta_{2}=.88\right]$, reflecting the fact that letter identification was better for the HF $(\mathrm{M}=86.2 \%)$ than for the LF $(\mathrm{M}=54.1 \%)$ words. A significant effect of fixation position was also found $\left[\mathrm{F}(4,92)=7.86 ; p<.001 ; \eta_{2}=.25\right]$. There were more correct identifications when the VP corresponded to the middle of the word (74.3\% in P2 and P3) than to the beginning (71.9\% in $\mathrm{P} 1)$ or the end $(65.7 \%$ and $58.1 \%$ in $\mathrm{P} 4$ and $\mathrm{P} 5$, respectively). There was no significant interaction between frequency and fixation position, $\mathrm{F}<1$.

CA-group. In the CA-group, the ANOVA revealed a significant effect of lexical frequency, $\left[\mathrm{F}(1,23)=61.54 ; p<.001 ; \eta_{2}=.73\right]$, with $90.1 \%$ identification for HF-words and 72.4\% for LF-words. As for the RL children, there was a main effect of fixation position $\left[\mathrm{F}(4,92)=11.353 ; p<.001 ; \eta_{2}=.33\right]$, with better performance for positions P2-P3 (87\%) than for the word-initial (83.3\%) and word-final positions $(79.9 \%$ and $69.1 \%$, for P4 and P5, respectively). No interaction was found between the two factors, $[\mathrm{F}(4,92)=1.56 ; p=\mathrm{ns}$. $]$.

Dyslexics. As beginning readers (RL children), the dyslexic children also exhibited a large main effect of lexical frequency $\left[\mathrm{F}(1,23)=290.48 ; p<.001 ; \eta_{2}=.93\right]$, with $81.4 \%$ identification for HF words and $42.5 \%$ for LF words. Dyslexic children identified $70.1 \%$ and $67.7 \%$ of the words at $\mathrm{P} 2$ and $\mathrm{P} 3$, respectively, vs. 58.3\% at $\mathrm{P} 1$ and $56.8 \%$ at $\mathrm{P} 4-\mathrm{P} 5$, [F (4, $\left.92)=7.17 ; p<.0001 ; \eta_{2}=.24\right]$. Interestingly, there was a significant frequency by fixation position interaction $\left[\mathrm{F}(4,92)=2.98 ; p=.02 ; \eta_{2}=.11\right]$, indicating that the frequency effect was larger at unfavourable positions. 
As can be seen in Figure 1a, the results revealed systematic differences in the height and shape of the normal readers' and dyslexic children's VP curves $[\mathrm{F}(2,69)=14.94 ; p$ $\left.<.001 ; \eta_{2}=.30\right]$. With respect to height, the mean percentage of correct word identifications was much lower for the dyslexics (61.9\%) and for the beginning readers (RL) $(68.8 \%)$ than for the skilled readers $(\mathrm{CA})(81.2 \%)$. Pairwise comparisons revealed that the group effect could be entirely explained by the fact that there was a difference between children with impaired or emerging reading skills (dyslexics and RL children, respectively) and skilled readers $\left(\mathrm{CA}\right.$ children) $\left[\mathrm{F}(1,69)=9.15 ; p<.001 ; \eta_{2}=.21\right]$, and no difference between dyslexics and RL group $[\mathrm{F}(1,69)=1.3 ; p=$ n.s. $]$. With respect to shape, dyslexics showed a weaker difference between fixating the beginning (P1) and the end of the word (P4-P5) compared with the other groups $(1.6 \%, 10.0 \%$, and $8.9 \%$, for dyslexics, RL and CA children, respectively $)^{6}$. Moreover, this effect was more pronounced for LF words in all groups $(2.7 \%$, $15.1 \%$, and $14.9 \%$, for dyslexics, RL and CA children, respectively). Pairwise comparisons revealed that the difference between $\mathrm{RL}$ and $\mathrm{CA}$ groups was non-significant $[\mathrm{F}<1]$ and that the interaction between the left-right asymmetry and the groups could be entirely explained by the overt opposition between normal readers (CA and RL) and dyslexic children [F (1, $69)=3.39 ; p<.05 ; \eta_{2}=.07$, and $\mathrm{F}(1,69)=4.76 ; p<.01 ; \eta_{2}=.03$, for low-frequency words only].

Figure 1(a,b). Accuracy (mean percentage of correct word identifications) as a function of group $(\mathrm{DD}=$ dyslexics; $\mathrm{CA}=$ chronological age control; $\mathrm{RL}=$ reading level control; $\mathrm{DD}+\mathrm{DCD}=$ children with dyslexia and $\mathrm{DCD} ; \mathrm{DCD}=$ children with $\mathrm{DCD}$ only) and five fixation positions (P1, P2, P3, P4, and P5). Errors bars represent standard errors.

\footnotetext{
${ }^{6}$ The values are reported by averaging word frequency.
} 


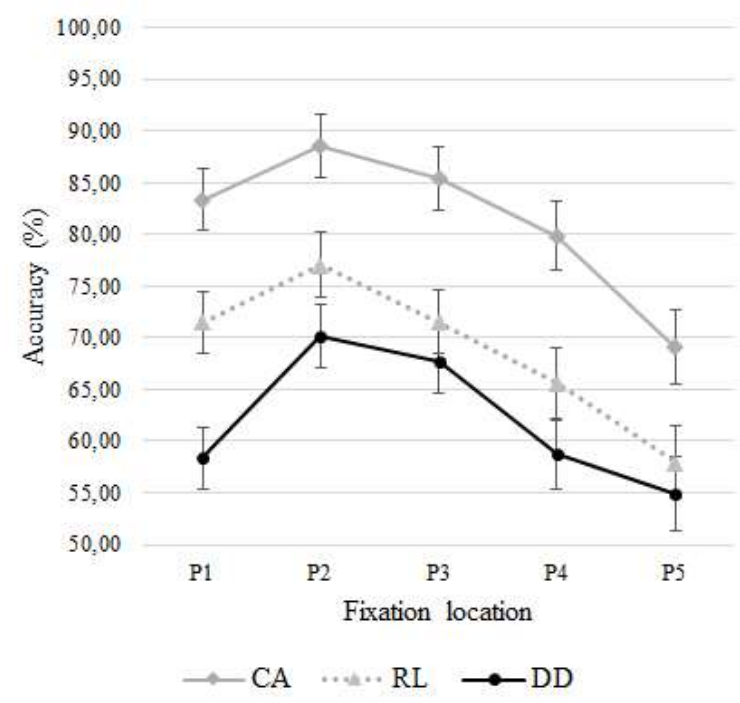

a)

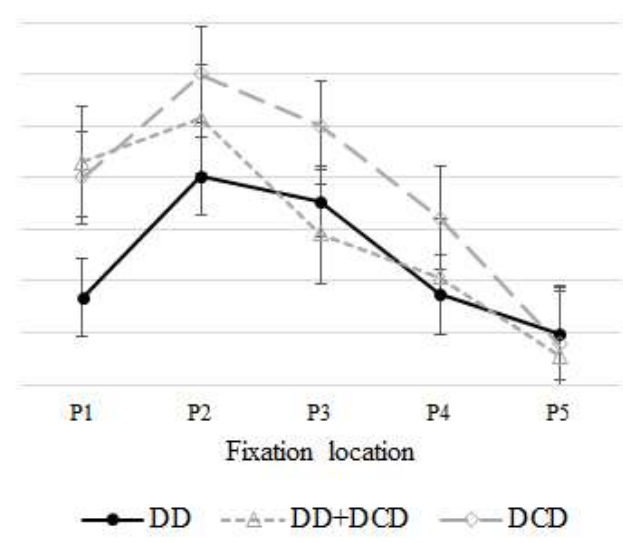

b)

STUDY 2 with DCD, and a group with both developmental disorders. Our goal was to explore the impact of co-occurring condition (DD+DCD) on OVP atypicalities.

\section{Method}

Participants. Three groups with neurodevelopmental disorders participated in this 
$=126.95 ; \mathrm{SD}=15.17)^{7}$, the other composed of 15 children with developmental coordination disorder $(\mathrm{DCD})($ mean age in months $=128.91 ; \mathrm{SD}=14.37)$ and the last one composed of 12 children with developmental dyslexia and developmental coordination disorder (DD+DCD)

391 (mean age in months $=126.77 ; \mathrm{SD}=11.55)$. They were all recruited and diagnosed in different hospitals or clinical centres based in France: La Timone University Hospital in Marseille, Kremlin-Bicêtre Hospital in Paris and the clinical centre "Les Lavandes" in Orpierre. They all underwent a complete medical, psychological and cognitive assessment. All participants were native speakers of French with normal or corrected-to-normal vision. Children whose oral language skills were in the pathological range or who were diagnosed with ADHD were excluded from the study.

Concerning children with DD and DCD, criteria for inclusion were manifest reading deficits [at least 1.5 SDs below the normal level on the "Alouette Test-R" (Lefavrais, 2005)] and IQ within the normal limits set by the diagnosis unit (IQ > 85), and no vision or hearing deficits. ANOVA analyses showed that the mean reading level of the dyslexic children (mean $=88 ; \mathrm{SD}=5.9$; months) were significantly lower than the DCD's mean reading level (mean=118.4; $\mathrm{SD}=23.5 ;$ months $)(p<.001)$ but were not significantly lower than that of the $\mathrm{DD}+\mathrm{DCD}$ children (mean= 89.6; $\mathrm{SD}=4.4$; months $)(p=$ n.s. $) . \mathrm{DD}+\mathrm{DCD}$ 's mean reading level was significantly lower than that of the DCD children $(p<.001)$ (ANOVA; Group effect $-F(2,22)=53.28 ; p<.001)$. Similarly, the dyslexic children's mean percentile on motor performance was significantly higher than those of the DCD and the DD+DCD children $($ mean $=35.15 ; \mathrm{SD}=23.15 ; p<.001)$. The difference between DCD (mean=1,71; $\mathrm{SD}=1.31)$ and $\mathrm{DD}+\mathrm{DCD}$ children (mean=3.57; $\mathrm{SD}=2.50)$ was not significant $(p=$ n.s.) (ANOVA; Group effect: $\mathrm{F}(2,18)=29.735 ; p<.001$ ).

\footnotetext{
${ }^{7}$ This was the same group of dyslexics who participated in Study 1.
} 

15 th percentile on the French version of the M-ABC (Soppelsa \& Albaret, 2004). Finally,

413

414 with regard to the DCD only group, we selected children who were diagnosed as DCD on the basis of the criteria listed above, i.e., score on the M-ABC below the 15th percentile, an IQ within the normal limits set by the diagnosis unit (IQ > 85), and no vision or hearing deficits. For this last group, we excluded children with DD or reading difficulties.

Material, task, stimuli and procedure. The same used in the Study 1. Exposure time for the target was about $150 \mathrm{~ms}$ for DCD children and $250 \mathrm{~ms}$ for DD and DD+DCD children.

\section{Data analysis}

In order to compare comorbid group to children with isolated disorders, we integrated in the analysis the group of dyslexic children of the Study 1. That is, the comparison has been made between three groups. Analysis of variance was thus run on the proportion of correct word identifications transformed in arcsine using a 2 Frequency x 5 Positions x 3 groups (dyslexics, children with developmental coordination disorder, and a group with both neurodevelopmental disorders) ${ }^{8}$. All factors, except Group, were within-participant factors. Effect sizes are reported as eta-square ( $\eta_{2}$, Bakeman, 2005).

The left-right asymmetry of the VP curves was measured and tested as in Study 1. Statistical analyses were conducted using the SPSS ${ }^{\circledR}$ program, version 20.0.

\footnotetext{
${ }^{8}$ The assumption of homogeneity of variance was not violated, all $p>.05$ (Levene's test).
} 
434 participants. Table 2 shows descriptive statistics of accuracy as a function of group, frequency 435 of words and letter position.

436

437 Table 2. Means and standard deviations of accuracy (percentage of correct responses) as a 438 function of group $(\mathrm{DD}+\mathrm{DCD}=$ children with dyslexia; $\mathrm{DCD}$; $\mathrm{DCD}=$ children with $\mathrm{DCD}$ only;

$439 \mathrm{DD}=$ dyslexics $)$, frequency of words $(\mathrm{HF}=$ High-frequency words; $\mathrm{LF}=$ Low-frequency

440 words), and five fixation positions (P1, P2, P3, P, and P5).

\begin{tabular}{lcccc} 
& & DD+DCD & DCD & DD \\
\hline & & mean $(\boldsymbol{S D})$ & mean $(\boldsymbol{S D})$ & mean $(\boldsymbol{S D})$ \\
\hline & P1 & $83.33(22.47)$ & $82.23(17.20)$ & $77.78(16.04)$ \\
& P2 & $88.88(19.26)$ & $90.01(15.16)$ & $89.58(15.40)$ \\
& P3 & $80.55(22.29)$ & $87.78(13.31)$ & $84.71(13.82)$ \\
& P4 & $80.55(19.89)$ & $87.78(17.21)$ & $75.00(23.04)$ \\
& P5 & $72.22(24.95)$ & $68.89(26.62)$ & $79.87(20.83)$ \\
& P1 & $59.73(25.09)$ & $57.77(20.76)$ & $38.90(22.35)$ \\
& P2 & $62.48(23.70)$ & $70.00(23.74)$ & $50.69(25.29)$ \\
& P3 & $48.63(19.42)$ & $62.21(20.38)$ & $50.70(28.85)$ \\
& P4 & $40.29(19.40)$ & $44.43(27.21)$ & $42.36(26.91)$ \\
& P5 & $33.33(22.48)$ & $38.89(34.88)$ & $29.86(22.50)$
\end{tabular}


Results showed a frequency effect $[\mathrm{F}(1,48)=422.01 ; p<.001 ; \eta 2=.89]$, meaning that accuracy was significant higher for high-frequency words $(81.9 \%)$ than for lowfrequency words $(47.6 \%)$, but this factor was not modulated by group $[\mathrm{F}(2,48)=1.675$; $p=$ n.s.], nor position $[\mathrm{F}<1]$. In addition, there was a main effect of fixation position [F (4, $192)=18.63 ; p<.001 ; \eta 2=.26]$, thus reflecting the fact that word identification was better in the middle of the word $(71.3 \%$ in $\mathrm{P} 2$ and $\mathrm{P} 3)$ than in the beginning $(64.9 \%$ in $\mathrm{P} 1)$ or the end (61.3\% and 54.9\% in P4 and P5, respectively). It also emerged a significant group by fixationposition interaction $[F(8,192)=2.14, p=.03 ; \eta 2=.06]$. As can be seen in Figure $1 b$, the results revealed systematic differences in the shape of the dyslexic children and other neurodevelopmental disorders' VP curves. As in Study 1, the asymmetry between the beginning (P1 and the end of the word, P4-P5) was less pronounced for dyslexics $(1.5 \%)$ compared with the other groups, $(10.0 \%, 14.5 \% \text {, for DCD and DD+DCD, respectively })^{9}$. Pairwise comparisons revealed that the difference between DCD and DD+DCD groups was non-significant $[\mathrm{F}<1]$ and that the interaction between the left-right asymmetry and the groups could be entirely explained by the difference between children with a motor deficit $(\mathrm{DCD}$ and $\mathrm{DD}+\mathrm{DCD})$ and dyslexic children $[\mathrm{F}(1,48)=3.976, p=0.03, \eta 2=0.07]$.

\section{DISCUSSION}

The present study explored early stages of visual word recognition in disabled and typically developing readers, using a fixation-contingent display. The first aim was to better understand the specificity of any OVP anomalies within DD by comparing dyslexics with two groups of typical developing readers, the first of which matched on chronological age (CA) and the second matched on reading level (RL).

\footnotetext{
${ }^{9}$ We reported here percentage by averaging word frequency.
} 
Results of Study 1 showed that the initial eye position on a word strongly affects the within-word behaviour for all groups. Firstly, as previously reported for adult readers (McConkie et al., 1989; O'Regan \& Jacobs, 1992; O'Regan et al., 1984), the likelihood of identifying a word was greater when the eyes initially fixate near the middle of words. This left-half advantage reflects right visual field (RVF) superiority, a finding previously obtained in languages written from left to right (see also, Aghababian \& Nazir, 2000; Ducrot et al., 2003; 2013; Dubois et al., 2007, for similar results). Like beginning readers, DD children exhibited a systematic variation in reading performance according to where their eyes were fixating in the word, suggesting that the system that supports normal reading was at least partly functioning. However, if we look separately at the height and shape of the dyslexics' and typical developing readers' VP curves we can observe some differences.

With respect to height, analyses showed that word recognition performance was significant lower for the DD group (61.9\%) than CA group $(81.2 \%)$; the same trend was observable between RL (68.8 \%) and CA groups. Here, the absence of significant differences between dyslexics and RL suggested that activation of lexical knowledge is not impaired in dyslexics, but at least weak, with poor lexicon for these two groups (Ducrot et al., 2003). Moreover, a word frequency effect emerged, modulated by the group. Particularly, results showed that the frequency effect was attenuated with the increase of reading skills. That is, the differences between high- and low-frequency words was larger for DD and beginning readers (here represented by the RL-control group) than for skilled readers (CA group) (38.9\% for dyslexics, $32.1 \%$ for RL children, and $17.7 \%$ for CA children). Accordingly, a more pronounced frequency effect has been already found in dyslexics compared to normal readers (e.g., Dubois et al., 2007; Durrwachter et al., 2010).

With respect to shape, the VP curve was affected by reading level, with a weaker P1 vs. P4-P5 asymmetry for DD compared to the other groups (see Dubois et al., 2007; Ducrot et 
al., 2003, for similar results). Moreover, the VP curve was also modulated by word frequency, this effect being more pronounced for LF words, thus suggesting a perceptual recognition probability curve explanation (McConkie et al., 1989). Accordingly, O'Regan and Jacobs (1992) previously showed that the cost of not fixating the OVP of words can be greater for LF words than for HF words. Note that unlike dyslexics, no interaction was found between fixation position and frequency for normal readers, were visuo-attentional and lexical factors were additive, in that frequency increased height equally for all viewing positions (e.g., McConkie et al., 1989; O’Regan \& Jacobs, 1992; Vitu, 1991). It can thus be argued that the frequency effect and its interactions with other variables increase as the quality of the presentation conditions, stimulus attributes, and/or participants' skills become poorer (see Ducrot et al., 2013 for similar results with beginning readers and Slattery \& Rayner, 2010, for a similar effect with text degradation). This interpretation is strengthened by the interaction between frequency and group described above, suggesting an attenuated frequency effect linked to an increase of reading skills.

Concerning the lack of left-right asymmetry in DD group, since the difference between RL and CA groups was non-significant, the interaction between the left-right asymmetry and the groups could be entirely explained by the overt opposition between normal readers (CA and RL) and dyslexic children. As stated in the Introduction section, the asymmetric inverted $J$-shape curve is linked to visuo-attentional processing in word recognition. In particular, it has been proposed that when the stimulus is discrete (like a word), the participant takes the direction of attentional scanning (left-to-right) into account, which results in asymmetrical landing-position pattern (Ducrot \& Pynte, 2002). Indeed, this suggest that reading habits have an influence on the shape and the asymmetry of VP curves (Nazir, Ben-Boutayab, Decoppet, Deutsch, \& Frost, 2004). Note that this left-half advantage also suggests that word beginning may play an important role in the word-identification OVP 
effect. Previous studies have demonstrated that the initial letter of a word provides a great deal of information, and knowledge of the initial letter is more effective than knowledge of the final letter for word identification (Brysbaert \& Nazir, 2005; Grainger, 2017; Stevens \& Grainger, 2003; White, 2008; Yan, Tian, Bai, \& Rayner, 2006). In our study, both the CAcontrol group and the RL-control group showed asymmetrical curve suggesting that an adultlike pattern is acquired very rapidly while learning to read, even after 1 year of exposure to reading (e.g., Aghababian \& Nazir, 2000; Bellocchi, Mancini, Jover, Huau, Ghio, André \& Ducrot, 2013a; Bellocchi et al., 2019; Ducrot, Pynte, Ghio, \& Lété, 2013). Particularly, beginning readers (here represented by the RL-control group) can extract visual information from words as proficient readers do. On the contrary, we found that DD children showed less asymmetry between P1 and P4-P5 compared to typically developing readers. In other words, in line with other data, DD showed a symmetrical curve (i.e., Aghababian et al., 2001; Ducrot et al., 2003; Montant et al., 1998). Dubois and colleagues (2007), as well as Aghababian and Nazir (2000) have already observed the same pattern of VP inverted $V$-shape curves for a single case surface dyslexic and poor beginning readers. According to the attentional scanning (left-to-right) hypothesis, the absence of left-right asymmetry in the VP curve suggests atypical processing of information outside of foveal vision for dyslexics, as Geiger and colleagues (1992) found, and could thus reflect a deficit in visuo-attentional processing. In that sense, Brannan and Williams (1987) showed that good readers and adults were significantly more accurate when the target appeared on the right side of a fixation point (RVF enhancement), but poor readers were equally accurate on the two sides. The absence of a left-right asymmetry in DD group comes very likely from the fact that dyslexics are not penalized when they see all the letters of a word (-1 letter) in their LVF, unlike normal readers, with their attentional window directed to the RVF, which are thus more penalized in this case. It seems however that DD do as well as other readers when all the letters of the 
word (-1 letter) are in their RVF, as ever noticed by Bellocchi and colleagues (2019).

Therefore, our data reinforced the idea that dyslexics' initial fixation position in word recognition is not "optimal" which can produce more frequent positioning errors, leading to more refixations than normal readers (Hawelka et al., 2010). Differences with RL group suggested non-optimal visuo-attentional strategies, given the left-to-right directionally and the asymmetric word structure of French.

In the second study, our goals were (1) to examine the visuo-attentional processing in children with DCD and (2) to explore the impact of co-occurring condition (DD+DCD) on OVP atypicalities. As observed in Study 1, results showed that for all groups, the probability of identifying the target word increased when the initial fixation was imposed on the left of the word centre $(71.3 \%$ in $\mathrm{P} 2$ and $\mathrm{P} 3)$ rather than to the word beginning/ending $(64.9 \%$, $61.3 \%$ and $54.9 \%$ in P1, P4 and P5, respectively). However, it is important to analyse the pattern of results taking into account the height and the shape of OVP curves, separately. Concerning the height, analyses showed no significant differences between groups in word recognition performance. The mean percentage of correct word identification was $61.9 \%, 65.0 \%$, and $69.0 \%$, for DD, DD+DCD and DCD, respectively. The mental lexicon seemed to be used in the same way by the three groups of children in word recognition ${ }^{10}$. As

${ }^{10}$ Alexis, Ducrot and Lété (2006) have ever noticed the fact that the height of the VPcurves was not greatly affected by the presence/absence of reading difficulties in DCD $60 \%$ and $57 \%$ of correct identifications for DCD and DD+DCD, respectively), thus suggesting that activation of lexical knowledge is not impaired in DD or in DD+DCD. It must be noted, however, that the exposure time used for the target display was significantly shorter for DCD children (150 ms vs. $250 \mathrm{~ms}$ for DD and DD+DCD children). 
in Study 1, robust effects of word frequency were obtained for all groups, confirming greater sensitivity to word frequency and poor lexical orthographic knowledge in children with learning disorders (see Dubois et al., 2007; Durrwachter et al., 2010; Hawelka et al., 2010). Note that this factor was not modulated by group, nor by VP. The frequency of occurrence of words changed the total height of the VP curves without affecting its shape, with the curves for HF words being above that for LF words (e.g., McConkie et al., 1989; O'Regan \& Jacobs, 1992; Vitu, 1991).

With respect to shape of VP curves, the manipulation of initial VP revealed differences between our three groups of children with neurodevelopmental disorders. In particular, the asymmetry between the beginning (P1) and the end of the word (P4-P5) was less pronounced for DD (1.5\%) compared with the other groups, $(10 \%, 14.5 \%$, for DCD and $\mathrm{DD}+\mathrm{DCD}$, respectively). In other words, contrary to what it is observed in DD group, DCD and DD+DCD groups showed typical left-right asymmetry in the VP curve. We observed better recognition performance when these children fixated regions in the word where the greatest number of letters could be recognized and where most words could be guessed, that is, left of centre. Visual-field asymmetries comparable to those observed in normal readers were evident for these two groups of children (DCD and DD+DCD), suggesting typical processing of information outside of foveal vision. Contrary to the expectation that the visuospatial deficits observed in DCD could lead to OVP atypicalities, our results suggest that visuo-attentional processing in word recognition seems to be not impaired in children with DCD, isolated or comorbid. Note that this is the first evidence of typical OVP effect (in terms of shape of the curve) in children with DCD or DD+DCD.

Looking at the impact of comorbidity, we did not find any additional effect on visuoattentional abilities associated with a dual diagnosis. Therefore, these data do not support the cumulative hypothesis according to which if co-morbid condition add to the severity of the 
cognitive deficit, children with DD and DCD should revealed more marked atypical VP curve than children with isolated DD (e.g., Pitcher et al., 2002). These results are in line with a bunch of recent studies suggesting that the comorbid condition does not systematically add to the severity of associated cognitive disorders (e.g., Bellocchi, Ducrot, Tallet, Jucla, \& Jover, 2021; Bellocchi et al., 2017; Biotteau, Albaret, Lelong, \& Chaix, 2017; Kaplan et al., 2006; Maziero, Tallet, Bellocchi, Jover, Chaix, \& Jucla, 2020). Conversely, our results showed that the comorbid DCD disorder seemed to balance the OVP atypicalities linked to reading deficits. Indeed, only children with isolated DD showed an inverted $V$-shape VP curve qualitatively different from the one showed by typically developing readers suggesting a specific profile in visuo-attentional processing linked to reading deficit in this neurodevelopmental disorder. One possible explanation is that this deficit results from particular scanning strategies linked to a lack of reading exposure, leading to difficulty to control the distribution of attention (Bellocchi et al., 2019; Brannan \& Williams, 1987; Ducrot et al., 2003; Facoetti, Turatto, Lorusso, \& Mascetti, 2001 ; Geiger et al. 1992; see Bellocchi et al., 2013b and Goswami, 2015 for reviews).

Finally, if we look at the VP curves (Figure 1b), we can notice that comorbid children seem to perform partially at an intermediate level between DD and DCD children. Indeed, the comorbid group“s VP curve begun at the level of DCD's one (which had typical reading abilities) and then joined the DD's curve. This result supports that co-morbid condition does not add to the severity of the cognitive deficit. Additionally, it corroborates the hypothesis on the impact of the amount of visual attention resources available for processing and the quantity of print exposure on the very earliest stages of visual word recognition.

Last but not least, our work allows us to bring out some interesting elements on clinical practice regarding both diagnosis and remediation of DD. Agreement is rising that 
reading difficulties can be due to impairments in different stages of the reading process, either in the visual or in the linguistic system. However, as Bellocchi et al. (2017) previously highlighted, at present, most of the tools available to professionals are designed for the assessment and remediation of child language problems. Furthermore, very few standardized tools today focus on the assessment of fine-grained visuo-attentional processes following experimental paradigms used in the scientific literature (but see, Ducrot et al., 2008; Leibnitz, Ducrot, Grainger, \& Muneaux, 2014; Valdois, Guinet, \& Embs, 2014). Accordingly, our paper demonstrated that the OVP paradigm provides an interesting way to better understand the nature of the visuo-attentional strategies involved in word recognition by children who have a learning disability. This paradigm allows detecting quantitative and qualitative differences in the VP curve of these children by a fine-grained analysis of the height and the shape of their VP curves.

Regarding the height and the quality of lexical processing, these results obtained on disabled readers indicate that activation of lexical knowledge was poorer in children with neurodevelopmental disorders compared to typically developing children. They also confirmed that reading difficulties are more likely to either increase frequency effects themselves or to increase frequency effects under particularly non-optimal conditions of presentation. When it comes to the shape, there was a drop in performance when the fixation point was shifted horizontally from the centre of the word for all groups. However, if typically developing readers have already developed highly automatized procedures of left-to-right attentional scanning which results in asymmetrical landing-position pattern (and a left-half advantage), the drop was not asymmetric for our DD. We argue that the inverted $V$-shape curve obtained in this group is a clinical marker of visuo-attentional difficulties in DD, likely linked to a limited experience with written language (see Bellocchi et al., 2019 for additional data supporting this hypothesis). Contrary to the expectation that the visuo-spatial deficits 
observed in DCD could lead to OVP atypicalities, our results suggest that visuo-attentional processing in word recognition is not impaired in children with $\mathrm{DCD}$, isolated or comorbid, at least with respect to the left-to-right attentional scanning procedure (i.e., they showed typical $J$-shape curve). This last result suggests that the OVP paradigm could be used as a clinical tool to identify possible OVP atypicalities that could be specific of some neurodevelopmental disorders (i.e., DD vs. DCD and DD+DCD). Again, this could constitute an important source of information for practitioners to differentiate cognitive profiles of children with DD, compared to children with DCD and DD+DCD disorders. The possibility of describing specific cognitive profiles in these populations is fundamental in view of establishing thorough and accurate assessment procedures and proposing an ad hoc remediation and intervention program that take into account the particular processes affected.

Summing up, our study showed that firstly, typically developing readers had already developed highly automatized procedures of left-to-right attentional scanning which results in asymmetrical landing-position pattern. Here, dyslexics showed a non-prototypical inverted $V$ shape VP curve, which might reflect visuo-attentional difficulties linked to reading difficulties and/or a lack of experience with written language. Secondly, contrary to the expectation that the visuo-spatial deficits observed in DCD could lead to OVP atypicalities, our results suggest that visuo-attentional processing in word recognition is not impaired in children with DCD, isolated or comorbid. Finally, given the absence of significant group differences between children with DD and DCD and children with isolated disorders (DD or DCD), our results reinforce the idea that the comorbid condition does not add to the severity of OVP anomalies. 
659

660

661

662

663

664

665

666

667

668

669

670

671

672

673

674

675

676

677

678

679

680

681

682

\section{References}

Aghababian, V., \& Nazir, T. A. (2000). Developing normal reading skills: Aspects of visual processes underlying word recognition. Journal of Experimental Child Psychology, 76, 123-150.

Aghababian, V., Nazir, T. A., Lançon, C., \& Tardy, M. (2001). From "Logographic" to Normal Reading: The Case Of a Deaf Beginning Reader. Brain and Language, $78,212-223$.

Alexis, C., Ducrot, S., \& Lété, B. (2006). La perception du mot écrit chez l'enfant dyspraxique. ANAE. Approche neuropsychologique des apprentissages chez l'enfant, 88$89,207-213$.

American Psychiatric Association (2013). Diagnostic and statistical manual of mental disorders (5th ed.). Washington, DC: Author.

Bakeman, R. (2005). Recommended effect size statistics for repeated measures designs. Behavior Research Methods, 37(3), 379-384.

Bellocchi, S., Ducrot, S., Tallet, J., Jucla, M. \& Jover, M. (2021). Effect of comorbid developmental dyslexia on oculomotor behavior in children with developmental coordination disorder: A study with the Developmental Eye Movement test. Human Movement Science, 76, 102764. doi: 10.1016/j.humov.2021.102764

Bellocchi, S., Mancini, J., Jover, M., Huau, A., Ghio, A., André, C., \& Ducrot. S. (AugustSeptember 2013a). Dyslexic readers and saccade computation: Effects of reading exposure and visuo-perceptual constraints. Poster presented at the XVIIIth ESCoP Conference. Budapest. Hungary.

Bellocchi, S., Massendari, D., Grainger, J., \& Ducrot, S. (2019). Effects of inter-character spacing on saccade programming in beginning readers and dyslexics. Child 

Neuropsychology. A Journal on Normal and Abnormal Development in Childhood and Adolescence, 25(4), 482-506.

Bellocchi, S., Muneaux, M., Bastien-Toniazzo, M., \& Ducrot, S., (2013b). I can read it in your eyes: What eye movements tell us about visuo-attentional processes in developmental dyslexia. Research in Developmental Disabilities, 34, 452-460.

Bellocchi, S., Muneaux, M., Huau, A., Lévêque, Y., Jover, M., \& Ducrot, S. (2017). Exploring the Link between Visual Perception, Visual-Motor Integration, and Reading in Normal Developing and Impaired Children using DTVP-2. Dyslexia. An International Journal of Research and Practice, 23(3), 296-315

Bennett, I. J., Romano, J. C., Howard Jr, J. H., \& Howard, D. V. (2008). Two forms of implicit learning in young adults with dyslexia. Annals of the New York Academy of Sciences, 1145(1), 184-198.

Biotteau, M., Albaret, J.M., Lelong, S., \& Chaix, Y. (2017). Neuropsychological status of French children with developmental dyslexia and/or developmental coordination disorder: Are both necessarily worse than one? Child Neuropsychology. A Journal on Normal and Abnormal Development in Childhood and Adolescence, 23(4), 422-441.

Blythe, H.I. (2014). Developmental changes in eye movements and visual information encoding associated with learning to read. Current Directions in Psychological Science, 23(3), 201-207.

Borella, E., Chicherio, C., Re, A. M., Sensini, V., \& Cornoldi, C. (2011). Increased intraindividual variability is a marker of ADHD but also of dyslexia: A study on handwriting. Brain and cognition, 77(1), 33-39.

Bosse, M. L., \& Valdois, S. (2009). Influence of the visual attention span on child reading performance: A cross-sectional study. Journal of Research in Reading, 32(2), 230-253. 
Brannan, J. \& Williams, M. (1987). Allocation of visual attention in good and poor readers. Perception \& Psychophysics, 41, 23-28.

Brysbaert, M., \& Nazir, T. A. (2005). Visual constraints on written word recognition: Evidence from the optimal viewing position effect. Journal of Research in Reading, 28(3), 216-228.

Brysbaert, M., Vitu, F., \& Schroyens, W. (1996). The right visual field advantage and the optimal viewing position: On the relation between foveal and parafoveal word recognition. Neuropsychology, 18, 385-395.

Chaix, Y., Albaret, J.M., Brassard, C., Cheuret, E., de Castelnau, P., Bénesteau, J., Karsenty, C., \& Démonet, J.F. (2007). Motor impairment in dyslexia: The influence of attention disorders. European Journal of Paediatric Neurology, 11, 368-374.

Clark, J. J., \& O'Regan, J. K. (1999). Word ambiguity and the optimal viewing position in reading. Vision Research, 39(4), 843-857.

Clark, J. J., \& O'Regan, J. K. (1999). Word ambiguity and the optimal viewing position in reading. Vision Research, 39(4), 843-857.

Danna, J., Massendari, D., Furnari, B., \& Ducrot, S. (2018). The optimal viewing position effect in printed versus cursive words: Evidence of a reading cost for the cursive font. Acta Psychologica, 188, 110-121. doi: 10.1016/j.actpsy.2018.06.003

Deutsch, A., \& Rayner, K. (1999). Initial fixation location effects in reading Hebrew words. Language \& Cognitive Processes, 14, 393-421.

Dubois, M. Lafaye De Micheaux, P., Noël, M. P. \& Valdois, S. (2007). Pre-orthographical constraints on visual word recognition: Evidence from a case study of developmental surface dyslexia. Cognitive Neuropsychology, 24(6), 623-660.

Ducrot, S., \& Grainger, J. (2007). Deployment of spatial attention to words in central and peripheral vision. Perception \& Psychophysics, 69(4), 578-590. 
Ducrot, S., \& Pynte, J. (2002). What determines the eyes' landing position in words? Perception \& Psychophysics, 64, 1130-1144.

Ducrot, S., Ghio, A., Michaël, G., Muneaux, M., Rauzy, S., \& Lété, B. (2008). The ADIVA (Aide au DIagnostic des déficits Visuo-Attentionnels chez l'enfant) software package. Unpublished Technical Report (69 p.), Aix-Marseille University.

Ducrot, S., Lété, B., Sprenger-Charolles, L., Pynte, J., \& Billard, C. (2003). The optimal viewing position effect in beginning and dyslexic readers. Current Psychology Letters : Behaviour, Brain and Cognition, 10, 1-10.

Ducrot, S., Pynte, J., Ghio, A., \& Lété, B. (2013). Visual and Linguistic Determinants of the Eyes' Initial Fixation Position in Reading Development. Acta Psychologica, 142, 287298.

Dürrwächter, U., Sokolov, A.N., Reinhard, J., Klosinski, G., \& Trauzettel-Klosinski, S. (2010). Word length and word frequency affect eye movements in dyslexic children reading in a regular (German) orthography. Annals of Dyslexia., 60(1), 86-101.

Facoetti, A., Turatto, M., Lorusso, M. L., \& Mascetti, G. G. (2001). Orienting of visual attention in dyslexia: Evidence for asymmetric hemispheric control of attention. Experimental Brain Research, 138, 46-53.

Farid, M., \& Grainger, J. (1996). How initial fixation position influences visual word recognition: A comparison of French and Arabic. Brain and Language, 53, 681-690.

Fawcett, A. J., \& Nicolson, R. I. (1995). Persistent deficits in motor skill of children with dyslexia. Journal of Motor Behavior, 27(3), 235-240.

Forster, K. I., \& Forster, J. C. (2001). DMDX version 2.9.01. Retrieved from internet from http://www.u.arizona.edu/ j jorster/dmdx.htm.

Franceschini, S., Gori, S., Ruffino, M., Pedrolli, K., \& Facoetti, A. (2012). A causal link between visual spatial attention and reading acquisition. Current Biology, 22, 814-819. 
Gagl, B., Hawelka, S., \& Hutzler, F. (2014). A similar correction mechanism in slow and fluent readers after suboptimal landing positions. Frontiers in Human Neuroscience, 8 , 355.

Geiger, G., Lettvin, J. Y., \& Zegarra Moran, O. (1992). Task-determined strategies of visual process. Cognitive Brain Research, 1, 39-52.

Goswami, U. (2015). Sensory theories of developmental dyslexia: Three challenges for research. Nature Review Neuroscience, 16, 43-54.

Goswami, U. C., \& Bryant, P. (1990). Phonological skills and learning to read. New-York : Psychology Press.

Grainger, J. (2017). Orthographic processing: A “mid-level” vision of reading. The Quarterly Journal of Experimental Psychology, 71 (2), 1-72.

Grainger, J., Dufau, S., \& Ziegler, J. C. (2016). A vision of reading. Trends in Cognitive Science, 20, 171-179.

Hawelka, S., Gagl, B., \& Wimmer, H. (2010). A dual-route perspective on eye movements of dyslexic readers. Cognition, 115, 367-379.

Huestegge, L., Radach, R., Corbic, D., \& Huestegge, S. (2009). Oculomotor and linguistic determinants of reading development: A longitudinal study. Vision Research, 49, 29482959.

Iversen, S., Berg, K., Ellertsen, B., \& Tønnessen, F. E. (2005). Motor coordination difficulties in a municipality group and in a clinical sample of poor readers. Dyslexia, 11(3), 217231.

Joseph, H.S.S.L.. Liversedge, S.P., Blythe, H.I., White, S.J., \& Rayner, K. (2009). Word length and landing position effects during reading in children and adults. Vision Research, 49, 2078-2086. 
Jover, M., Ducrot, S., Huau, A., Bellocchi, S., Brun-Hénin, F., \& Mancini, J. (2013). Les troubles moteurs chez les enfants dyslexiques : Revue de travaux et perspectives. Enfance, 4, 323-347.

Kajii, N., \& Osaka, N. (2000). Optimal viewing position in vertically and horizontally presented Japanese words. Perception \& Psychophysics, 62(8), 1634-1644.

Kaplan, B. J., Dewey, D. M., Crawford, S. G., \& Wilson, B. N. (2001). The term comorbidity is of questionable value in reference to developmental disorders: Data and theory. Journal of Learning Disabilities, 34(6), 555-565.

Kaplan, B., Crawford, S., Cantell, M., Kooistra, L., \& Dewey, D. (2006). Comorbidity, cooccurrence, continuum: What's in a name? Child: Care, Health and Development, $32(6), 723-731$.

LaBerge, D., \& Samuels, S.J. (1974). Toward a theory of automatic information process in reading. Cognitive Psychology, 6, 293-323.

Lam, S. S., Au, R. K., Leung, H. W., \& Li-Tsang, C. W. (2011). Chinese handwriting performance of primary school children with dyslexia. Research in Developmental Disabilities, 32(5), 1745-1756.

Lavidor, M., \& Walsh, V. (2004). The nature of foveal representation. Nature Reviews Neuroscience, 5, 729-735.

Lefavrais, P. (2005). Test de l'Alouette-R. Paris : ECPA.

Legge, G. E., Ahn, S. J., Klitz, T. S., \& Luebker, A. (1997). Psychophysics of reading-XVI. The visual span in normal and low vision. Vision Research, 37, 1999-2010.

Leibnitz, L., Ducrot, S., Grainger, J., \& Muneaux, M. (2014). Une batterie informatisée de dépistage des difficultés visuo-attentionnelles à destination des enfants de maternelle. Proceedings of the APPREC Conference, Learning Written Language: Diversity of languages, Uniqueness of disorders, December 3-5, Strasbourg, France. 
Lété, B., Sprenger-Charolles, L., \& Colé, P. (2004). Manulex: A grade-level lexical database from French elementary-school readers. Behavior Research Methods, Instruments, \& Computers, 36, 156-166.

Li, X., Liu, P., \& Rayner, K. (2011). Eye movement guidance in Chinese reading: Is there a preferred viewing location? Vision Research, 51, 1146-1156.

MacKeben, M., Trauzettel-Klosinski, S., Reinhard, J., Durrwachter, U., Adler, M., \& Klosinski, G. (2004). Eye movement control during single-word reading in dyslexics. Journal of Vision, 4(5), 388-402.

Maziero, S., Tallet, J., Bellocchi, S., Jover, M., Chaix, Y. \& Jucla, M. (2020). Influence of Comorbidity on Working Memory Profile in Dyslexia and Developmental Coordination Disorder. Journal of Clinical and Experimental Neuropsychology, 42(7), 660-674.

McConkie, G. W., Kerr, P. W., Reddix, M. D., Zola, D., \& Jacobs, A. M. (1989). Eye movement control during reading: II. Frequency of refixating a word. Perception \& Psychophysics, 46, 245-253.

McConkie, G.W., Kerr, P.W., Reddix, M.D., \& Zola, D. (1988). Eye movement control during reading: The location of initial eye fixations on words. Vision Research, 27, 227240.

Montant, M., Nazir, T. A., \& Poncet, M. (1998). Pure alexia and the viewing position effect in printed words. Neuropsychology, 15(1-2), 93-140.

Nazir, T. A., Jacobs, A. M., O’Regan, J.K. (1998). Letter legibilityand visual word recognition. Memory and Cognition, 26(4), 810-821.

Nazir, T. A. (2000). Traces of print along the visual pathway. In A. Kennedy, R. Radach, D. Heller, \& J. Pynte (Eds.). Reading as a perceptual process (pp. 3-23). Oxford: Elsevier. 
Nazir, T. A. (2003). On hemispheric specialization and visual field effects in the perception of print: A comment on Jordan, Patching and Thomas. Cognitive Neuropsychology, 20, 7380.

Nazir, T. A., Ben-Boutayab, N., Decoppet, N., Deutsch, A., \& Frost, R. (2004). Reading habits, perceptual learning, and recognition of printed words. Brain and Language, 88, 294-311.

Nazir, T. A., O'Regan, J. K., \& Jacobs, A. M. (1991). On words and their letters. Bulletin of the Psychonomic Society, 29, 171-174.

Nicolson, R. I., \& Fawcett, A. J. (1994). Comparison of deficits in cognitive and motor skills among children with dyslexia. Annals of Dyslexia, 44(1), 147-164.

O'Hare, A., \& Khalid, S. (2002). The association of abnormal cerebellar function in children with developmental coordination disorder and reading difficulties. Dyslexia, 8(4), 234248.

O'Regan, J. K., \& Jacobs, A. M. (1992). Optimal viewing position effect in word recognition: A challenge to current theory. Journal of Experimental Psychology. Human Perception and Performance, 18, 185-197.

O'Regan, J. K., Lévy-Schoen, A., Pynte, J., \& Brugaillère, B. (1984). Convenient fixation location within isolated words of different length and structure. Journal of Experimental Psychology. Human Perception and Performance, 10, 250-257.

Pitcher, T. M., Piek, J. P., \& Barrett, N. C. (2002). Timing and force control in boys with attention deficit hyperactivity disorder: Subtype differences and the effect of comorbid developmental coordination disorder. Human Movement Science, 21(5-6), 919-945.

Rayner, K. (1979). Eye guidance in reading: Fixation location within words. Perception, 8, 21-30. 
853

854

855

856

857

858

859

860

861

862

863

864

865

866

867

868

869

870

871

872

873

874

875

Rogé, B. (1984). Manuel de l'échelle de développement moteur de Lincoln-Oseretsky. Paris: ECPA.

Schroeder, S., Hyönä, J., \& Liversedge, S. P. (2015). Developmental eye-tracking research in reading: Introduction to the Special Issue. Journal of Cognitive Psychology, 27(5), 500510.

Soppelsa, R., \& Albaret, J.-M. (2004). Manuel de la Batterie d'Evaluation du Mouvement chez l'Enfant (MABC). Paris: ECPA.

Stenneken, P., van Eimeren, L., Keller, I., Jacobs, A. M., \& Kerkhoff, G. (2008). Taskdependent modulation of neglect dyslexia? Novel evidence from the viewing position effect. Brain Research, 1189, 166-178.

Stevens, M., \& Grainger, J. (2003). Letter visibility and the viewing position effect in visual word recognition. Perception \& Psychophysics, 65(1), 133-151.

Stevens, M., \& Grainger, J. (2003). Letter visibility and the viewing position effect in visual word recognition. Perception \& Psychophysics, 65(1), 133-151.

Tsai, C. L., \& Wu, S. K. (2008). Relationship between visual-perceptual deficits and motor impairments in children with developmental coordination disorder. Perceptual and Motor Skills, 107, 457-472.

Tsai, C.L. (2009). The effectiveness of exercise intervention on inhibitory control in children with developmental coordination disorder: using a visuospatial attention paradigm as a model. Research in Developmental Disabilities, 30(6), 1268-80.

Valdois, S. Guinet, E., \& Embs, J. L. (2014). EVADYS: Outil diagnostic des troubles de l'empan VA (EVADYS: a diagnostic tool for VA span assessment). Isbergues, France : Ortho-Edition. 
Valdois, S., Bosse, M. L., \& Tainturier, M. J. (2004). The cognitive deficits responsible for developmental dyslexia: Review of evidence for a selective visual attentional disorder. Dyslexia, 10, 339-363.

Velay, J. L., Daffaure, V., Giraud, K., \& Habib, M. (2002). Interhemispheric sensorimotor integration in pointing movements: A study on dyslexic adults. Neuropsychologia, $40(7), 827-834$.

Vernet, M., Bellocchi, S., Leibnitz, L., Chaix, Y., \& Ducrot, S. (2021). Predicting Future Poor Readers from Pre-reading Visual Skills: A Longitudinal Study. Applied Neuropsychology: Child.

Vitu, F. (1991). The existence of a center of gravity effect during reading. Vision Research, 31(7/8), 1289-1313.

Vitu, F., O'Regan, J. K., \& Mittau, M. (1990). Optimal landing position in reading isolated words and continuous text. Perception \& Psychophysics, 47, 583-600.

Vorstius, C., Radach, R., \& Lonigan, C.J. (2014). Eye movements in developing readers: A comparison of silent and oral sentence reading. Visual Cognition, 22(3-4), 458-485.

Wechsler, D. (2005). Echelle d'Intelligence pour Enfants et Adolescents, 4ème édition. Paris: ECPA.

White, S. J. (2008). Eye movement control during reading: Effects of word frequency and orthographic familiarity. Journal of Experimental Psychology: Human Perception and Performance, 34(1), 205.

Wilson, P. H., \& McKenzie, B. E. (1998). Information processing deficits associated with developmental coordination disorder: A meta-analysis of research findings. Journal of Child Psychology and Psychiatry, 39, 829-840. 
899 Wong, Y.K. \& Hsiao, J.H. (2012). Reading direction is sufficient to account for the optimal 900 viewing position in reading: The case of music reading. Proceedings of the Thirty-Fourth $901 \quad$ Annual Meeting of the Cognitive Science Society.

902 World Health Organisation. (1992). The ICD-10 classification of mental and behavioural 903 disorders. Clinical descriptions and diagnostic guidelines. Geneva: WHO.

904 World Health Organisation. (2008). 59th general assembly. In: Association WM, editor. 905 Seoul, Korea: WHO.

906 Yan, G., Tian, H., Bai, X., \& Rayner, K. (2006). The effect of word and character frequency 907 on the eye movements of Chinese readers. British Journal of Psychology, 97(2), 259-268. 